\title{
RoboSTEAM Project Systematic Mapping: Challenge Based Learning and Robotics
}

\author{
Miguel Á. Conde \\ Department of Mechanics, Computer \\ Science and Aerospace Engineering \\ University of León \\ León, Spain \\ mcong@unileon.es \\ José Gonçalves \\ Department of Electrical Engineering \\ Instituto Politécnico de Bragança \\ Bragança, Portugal \\ goncalves@ipb.pt
}

\author{
Francisco J. Rodríguez Sedano \\ Department of Electric, Systems and \\ Automatics Engineering \\ University of León \\ León, Spain \\ fjrods@unileon.es \\ José Lima \\ Department of Electrical Engineering \\ Instituto Politécnico de Bragança \\ Bragança, Portugal \\ jllima@ipb.pt
}

\author{
Camino Fernández-Llamas \\ Department of Mechanics, Computer \\ Science and Aerospace Engineering \\ University of León \\ León, Spain \\ cferll@unileon.es \\ Francisco J. García-Peñalvo \\ Grupo GRIAL \\ University of Salamanca \\ Salamanca, Spain \\ fgarcia@usal.es
}

\begin{abstract}
STEAM Education is nowadays a key element for our current digital society. Integrating STEAM and developing competences such as Computational Thinking is highly demanded by the industry and higher education institutions. In order to do so new methodological approaches are required. RoboSTEAM project is an Erasmus + project defined to address these topics by using of physical devices and robotics employing Challenge Based Learning methodology. One of the first steps in the project development is the definition of current landscape in the research field. Which means to carry out a literature mapping that considers previous applications of Challenge Based Learning in STEAM education and use of robots and physical devices to do so. This paper shows the mapping review process and the main results obtained. The mapping analyze 242 candidate works from the most relevant bibliographic sources and selected 54. Form them it was possible to see that there are not many initiatives on STEM Education related to Challenge base learning and the most of them are specially focused on the application of specific tools and in the development of concrete competences.
\end{abstract}

Keywords-Robotics, Physcal Devices, Systematic Mapping, Challenge Based Learning, STEAM Education

\section{INTRODUCTION}

Education is a critical issue in any society and teaching and learning processes should be adapted to the requirements and reality of the context where they are developed. Nowadays we are immersed in which is known as Digital Society and there is a need of professionals ready to address the problems that arise in it, which require that they have a deep knowledge about the methodologies, tools, devices to be used in each situation $[1,2]$.

Given this context the students (as future workers) need to develop several skills that later can increase their employability, such as critical thinking, teamwork, problemsolving, creativity [3-5] and also to acquire competences related to our current context, as Computational Thinking [3]. This necessity is addressed by what is understood as STEM (Science, Technology, Engineering and Mathematics) or STEAM (adding Arts to the equation) Education but integrating it into our current learning pathways is very difficult, because it goes beyond the definition of a new subject or a set of subjects. This requires of new learning methodologies and tools [1].
In this sense active and collaborative methodologies are specially relevant and a sample of them could be Project Based Learning - PBL [4], Project Based Learning - PrBL [5] and Challenge Based Learning - ChBL [6]. With these methodologies in mind and taking into account the idea that the definition of tangible solutions can be really interesting for the students, something that can be achieved with Physical Devices and Robotics (PD\&R) [7-10], the RoboSTEAM project was defined [11].

RoboSTEAM is an Erasmus + Strategic Partnership project that involves 8 partners from 4 different countries (4 schools and 4 universities). It aims to define a methodology and a set of tools that help learners to develop computational thinking by using/programming PD\&R in pre-university education stages. The project will also improve teacher education, providing them with a framework for easy STEAM integration in different educational contexts, by providing guidelines for good practices and lessons learned adapted to those contexts. All these products will be tested in different countries and cross-validated in different educational institutions [12]. This will be done through a set of pilots and by the exchange of students and teachers between the schools involved in the project.

The project development consists of several activities and different outcomes are expected. One of them was Output2, "Guides for designing Open Hardware PD\&R". The output aims to define guides that allow designing learning challenges for the development of STEAM competencies and computational thinking by using PD\&R. To achieve this, the researchers need a previous knowledge of the existing technology and what to apply depending on students' age or context. Given this fact, it is necessary to explore the current landscape regarding the project topic and to do that the project team carried out a literature review.

To carry out an analysis of the existing works Systematic Mapping (SMP) was carried out. The main goal of a systematic mapping study is to provide an overview of a research area, and identify the quantity and type of research and results available within it. The SMP provides a structure of the type of research reports and results that have been published by categorizing them and often gives a visual summary, the map, of its results. It often requires less effort than other methodologies while providing a more coarsegrained overview $[13,14]$. 
As the project requires to understand the existing landscape of PD\&R application, the partners decided that the mapping could be a more suitable option. The main objective of this review is to collect and analyze the existing works related to the application of PD\&R in education. This paper aims to describe the Systematic Mapping process and main results. The rest of this work is structured as follows. The next section presents the mapping methodology. In the third section the results are described and finally some conclusions are posed.

\section{Methodology}

The main phases of the systematic mapping are planning, conducting and reporting. In this section each of them is described.

\section{A. Planning}

We are applying a systematic mapping following a software engineering strategy. Hence, the principal topic and aims of the mapping were fixed, research domain was explored (which define what issues should be addressed by the review), and selection criteria were set up (which describe the works to include or exclude from the review). Finally, an analysis was undertaken of the results emerging from the review. Fig 1 shows, the different steps followed.

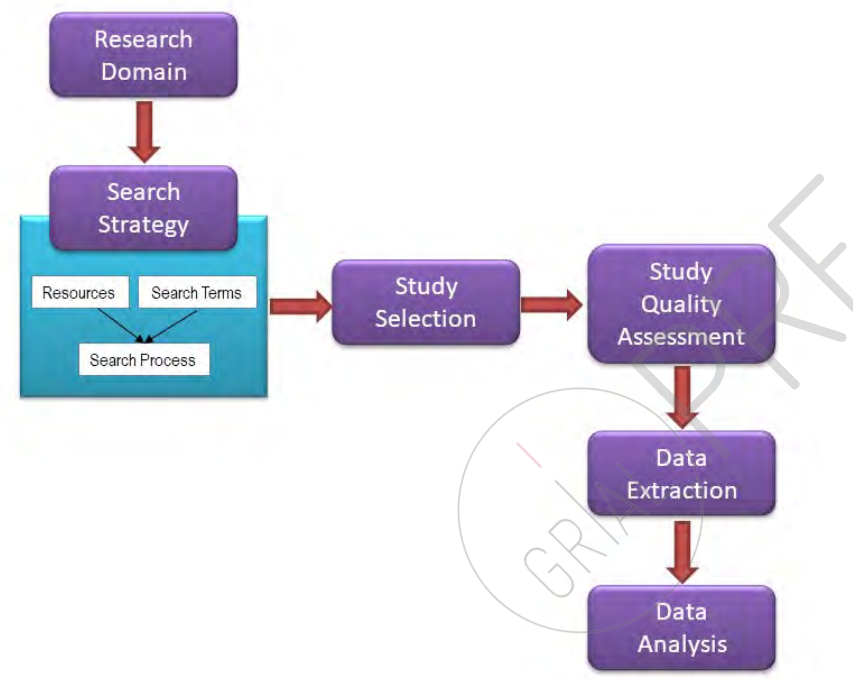

Fig. 1. Planning Process.

\section{1) Research domain}

In this first step it is necessary to set up the issues to explore during the mapping in order to clarify the landscape of the project. Given the project objectives the main issues were:

- Find existing initiatives or projects that apply Robotics or Mechatronics for the development of computational thinking or STEM in education.

- Explore if any of these these initiatives apply learning methodologies based on challenges.

\section{1) Search String}

Once defined the research domain the next step is the definition of the search string. The terms used in the searches depended on the research question being addressed, though in many instances these were shared. Searches were made for the following terms:

- "Robotics", either alone or in combination with the terms "mechatronics" or "physical devices".

- "Education".

- "STEAM" or the similar term "STEM".

- "Computational thinking", whether on its own or combined with "challenge based learning" or its abreviature "CBL"; "Problem-based Learning" or "Project-based Learning" or "Problem Based Learning" or "Project Based Learning" or its abreviature "PBL".

In building up the search strings for the various different libraries, the terms listed above were combined using the Boolean AND operator. An example could be:

(("robotics" OR "mechatronics" OR "physical devices") AND Education AND ("STEAM" OR "STEM") AND ("Computational Thinking" OR "Challenge Based Learning" OR "CBL" OR "Problem-based Learning" OR "Project-based Learning" OR "Problem Based Learning" OR "Project Based Learning" $O R$ "PBL"))

However, because of the variable nature of the search services and the variety of available library sources, it became clear that it was not possible to use a single search string for all the bibliographic sources. For example, in searching the ACM Digital Library, it was necessary to build up various search strings in order to seek items on a basis that could be considered equivalent to other sources (like IEEE Digital Library or Science Direct). Hence, the decision was to design and use different search strings for different sources.

2) Sources

The next step in the planning process was the selection of bibliographic sources. In this case those chosen were:

- $\mathrm{ACM}$ Digital (https://dl.acm.org/advsearch.cfm)

Library

- IEEE Digital Library (https://ieeexplore.ieee.org/)

- ISI Web of Science (http://www.isiknowledge.com)

- SCOPUS (https://www.scopus.com/)

- Springer Link (http://link.springer.com)

The reason to use these sources is that they are the most complete (specially web of science or scopus) and popular in the context of PD\&R and ICT and Education (ACM, IEEE and Springer).

\section{3) Inclusion and exclusion criteria}

Once the bibliographic sources were chosen the next step was defining the inclusion and exclusion criteria in order to carry out the selection study. During this part of the process and having these criteria, paper titles and or abstracts should be analyzed to know if they met the inclusion criteria, or whether on the contrary they should be excluded from further study.

The inclusion criteria defined for the mapping were:

- IC1. Include one or more of the keywords, have an appropriate structure and some type of implementation initiative. 
- IC2. Include one or more of the terms related to the topics included in the research questions.

- IC3. Paper published in a peer review journal or conference.

- IC4. Published after the year 2.000.

- IC5. Written in English.

On the other hand, the exclusion criteria were:

- EC1. Documents that covered the subject area and included the search terms, but did not answer the research questions.

- EC2. Documents that included keywords but only to redefine general concepts.

- EC3. The paper is not accessible.

- EC4. It is not an article.

- EC5. Papers not published in a peer review journal or conference.

\section{4) Quality Assesment Checklist}

From the papers selected after analyzing how they met the inclusion and exclusion criteria; the following step is to analyze the quality of the papers as a second to choose those of acceptable quality for later use in the extraction of data.

Questions:

- QC1. Does the paper describe the application of PD\&R in education?

- QC2. Is the paper based on research or is it merely a report based on expert opinion)?

- QC3. Is there a description of the context in which the research was carried out?

- QC4. Was the research design appropriate to address the aims of the research?

- QC5. Was the recruitment strategy appropriate to the aims of the research?

- QC6. Was there a control group with which to compare the results?

- QC7. Was the data collected in a way that addressed the research issue?

- QC8. Is there a clear statement of findings?

- QC9. Is the study of value for research or practice?

- QC10. Was the data analysis sufficiently rigorous?

- QC11. Is there a clear statement of the aims of the research?

All the question except the first one followed a scale that assessed the quality of the items reviewed with only three possible answers "YES", "PARTLY" or "NO". These grades were quantified as scores by assigning a value of 1 for "YES", 0.5 for "PARTLY" and 0 for "NO". The first question that is the most relevant for this research can be valued from 0-10.

\section{5) Data Extraction Form}

Once the elements that met the established quality criteria were selected, the next step was to extract the data from these works address the main issues identified. For this, a form with the following mapping questions were chosen.

- MQ1. Which are the main applications of robots and physical devices to develop STEAM and computational thinking?

- MQ2. Which are the most relevant authors, sources and location?

- MQ3. Classify the applications by physical device (Robots and type of robots and physical devices).

- MQ4. Classify the methodology applied:

○ Challenge Based Learning.

○ Problem Based Learning.

○ Project Based Learning.

Answering these questions, it will be easy to analyze the remaining paper and look for information about how they deal with the topics that the project is dealing with.

\section{B. Conducting}

The conducting phase implies the application of the instruments defined during the planning in order establish which is the most relevant literature for a later affordable analysis. The results obtained during the conducting phase can be seen in Fig 2.

Search Phase 1: This involved individual searching in the electronic databases previously commented and then gathering those papers that can be understood as suitable works for the mapping.

- Selection Phase 1: During this phase the inclusion and exclusion criteria were applied to the candidate papers in order to identify relevant articles that would provide the data for answering the research questions posed during the planning stage.

- Search Phase 2: It requires analyzing the references lists of the relevant articles to find further documents that might also be considered significant. After this analysis those suitable papers will be included in the relevant works set.

- Selection Phase 2: This phase applied quality assessment criteria to relevant documents with the aim of choosing those of acceptable quality for later use in extracting data.

Fig 2. Shows the distribution of papers from each source that define an initial set of 242 candidate papers, that after applying the inclusion and exclusion criteria (Fig 2. A) were reduced to 117 that later include 12 more papers (search phase 2 - Fig 2 . B) to reach 129 works (Fig 2. C), that after the selection phase 2 (Fig 2. D) were reduced to 54 works. 


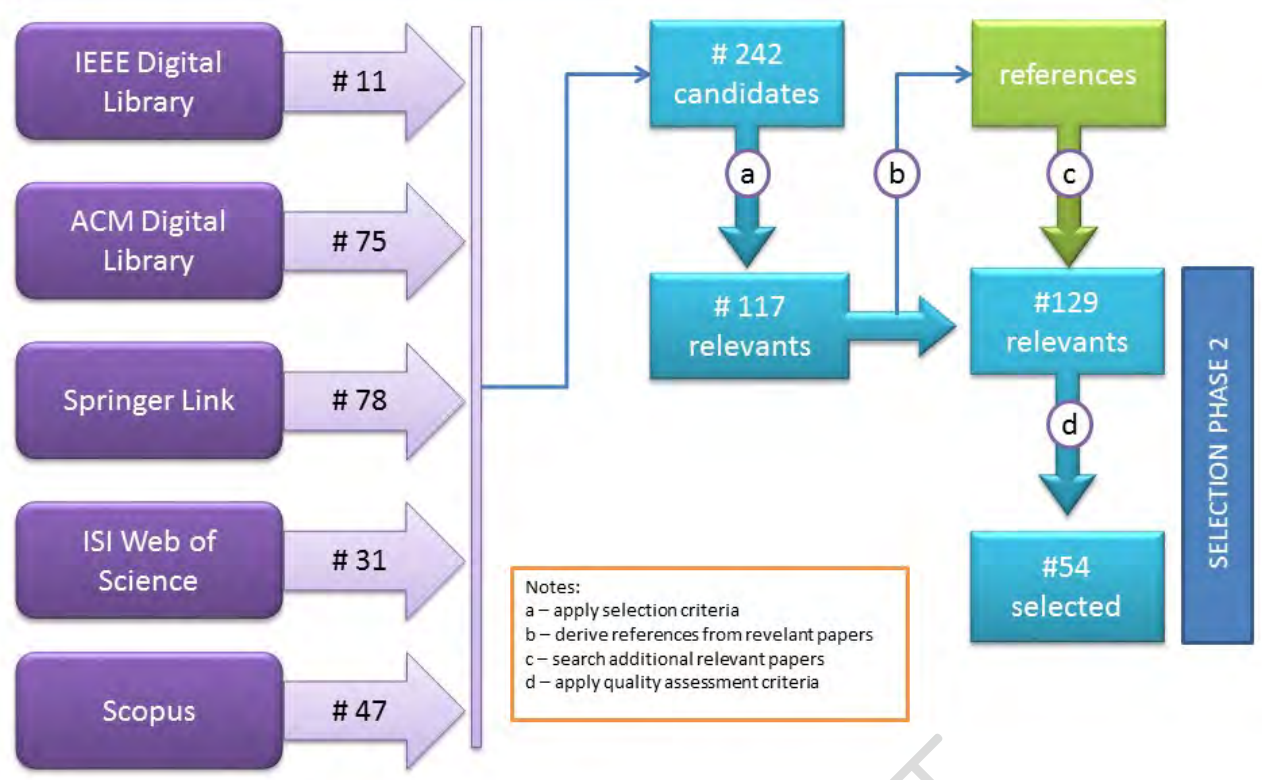

Fig. 2. Search and selection process.

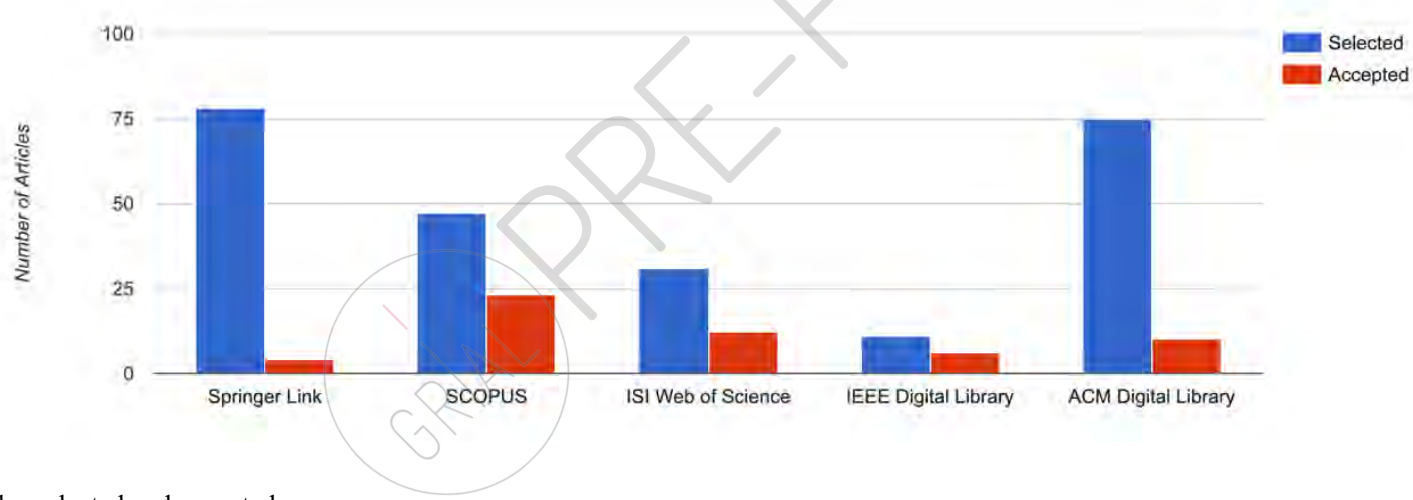

Fig. 3. Articles selected and accepted per source

\section{RESULTS}

The reporting part of the methodology include the results of the mapping which is discussed in this section. To presents the results first we show a quantitative distribution of the works and later the results answering each of the mapping questions.

\section{A. Quantitative Distribution}

A distribution of accepted articles per source could be seen in Fig 3. It is possible to see that the most relevant source has been SCOPUS, followed by WOS, because although initially we found several papers in Springer Link most of there were rejected.

If we attend to the number of publications per year (Fig 4.), and taking into account only works after 2000 (as decided by the researchers in IC4) we can see that from 2013 to 2019 there is a higher quantity of works related to the mapping topics.

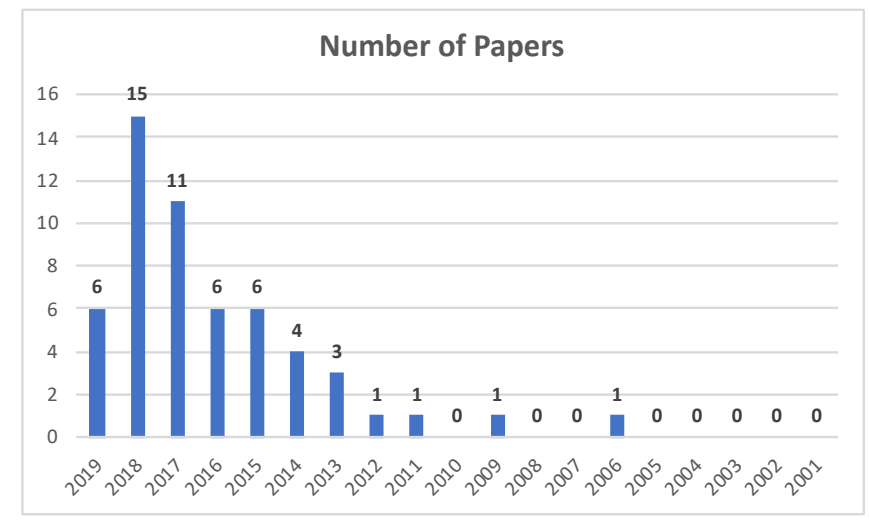

Fig. 4. Number of papers per year 
B. MQ1 - Which are the main applications of robots and physical devices to develop STEAM and computational thinking?

Taking into account the first question, the main applications can be divided into four topics:

- Topic 1. Papers that describe the effects of the application of robotics in education by using methodologies such as Project Based Learning (PrBL), Challenge Based Learning (ChBL) or Problem based learning (PBL).

- Topic 2. Papers specially focused on describing the application of PD\&R to foster STEAM disciplines.

- Topic 3. Developing computational thinking skills by applying PrBL, PBL or ChBL and using PD\&R.

- Topic 4. Works that applies different tools and techniques in the field of STEAM Education but special focused on the development of PD\&R, Evaluation Tools, Educational Tools.

The papers per topic can be seen in Table 1. With more emphasis in the papers related to competence development and in the tools to facilitate it.

\section{MQ2.- Which are the most relevant authors, sources and location?}

Regarding the authors, the selected papers have a total of 210 authors. From them, those with more than 1 publication between the studied papers are Amy Eguchi $[15,16]$ and Andrea Gomoll, Selma Šabanović, Cindy E. Hmelo-Silver and Matthew Francisco [17, 18].

Most of the publications comes from the USA, followed by Spain. Regarding the types of publications 29 contributions are conference proceedings, 24 contributions are journals and 2 are book chapters. The conferences with more publications among the selected papers are the ASEE (American Society for Engineering Education) Annual Conference and Exposition with 4 papers, the IEEE Integrated STEM Conference with 3 papers and others with 2 papers such as Frontiers in Education, the ACM technical symposium on Computer Science Education or the Annual Conference on Creativity and Fabrication in Education. Regarding the journals the Journal of Science Education and Technology with 3 contributions and the International Journal of Technology and Design Education with 2. The rest of the papers are published in other proceedings and journals.

\section{MQ3 - Classify the applications by physical device (Robots and type of robots and physical devices).}

The experiments described by the selected papers employ Robotics and Physical Devices (also known as Mechantronics). The distribution of the papers based on the used device can be seen in Table 2. It should be noted that some of the studied works can apply both robotics and physical devices.
TABLE 1. NUMBER OF PAPERS PER TOPIC AND REFERENCES.

\begin{tabular}{|c|c|c|}
\hline TOPIC & $\begin{array}{c}\mathbf{N}^{\mathbf{0}} \\
\text { PAPERS }\end{array}$ & REFERENCES \\
\hline Topic 1 & 8 & {$[16,17,19-24]$} \\
\hline Topic 2 & 23 & {$[15,16,18,22,24-42]$} \\
\hline Topic 3 & 17 & {$[27,31,36,38,41,43-54]$} \\
\hline Topic 4 & 19 & {$[28,30,42,44,46,55-68]$} \\
\hline
\end{tabular}

TABLE 2. DISTRIBUTION OF SELECTED PAPERS DEPENDING ON THE EMPLOYED DEVICES

\begin{tabular}{|c|c|c|}
\hline $\begin{array}{l}\text { Tool } \\
\text { Employed }\end{array}$ & $\begin{array}{l}\text { Number of } \\
\text { works }\end{array}$ & References \\
\hline Robotics & 26 & {$[15-18,20,21,23,25$,} \\
& & $\begin{array}{c}29-31,33-36,38,39,43- \\
46,48,49,57,59-62]\end{array}$ \\
\hline Physical & 15 & {$[26,27,40,41,51-54,56$,} \\
Devices & & $63-66,68]$ \\
\hline Both & 13 & {$[19,22,24,28,32,35$,} \\
& & $37,42,47,50,55,58,67]$ \\
\hline
\end{tabular}

TABLE 3. DISTRIBUTION OF SELECTED PAPERS BY THE APPLIED METHODOLOGY

\begin{tabular}{|l|l|l|}
\multicolumn{2}{c}{} & \multicolumn{1}{c|}{ METHODOLOGY } \\
\hline Methodology & $\begin{array}{l}\text { Number } \\
\text { of works }\end{array}$ & References \\
\hline PBL & 14 & {$[18,19,21,24,27,30$,} \\
& & $31,36,50-54,57]$ \\
\hline PrBL & 29 & $\begin{array}{l}{[16,20,21,23-27,32-} \\
35,37,39-45,47,55,\end{array}$ \\
& & $56,59-61,63-65]$ \\
\hline ChBL & 9 & {$[15,17,28,38,48,62$,} \\
& & $66-68]$ \\
\hline Other & 3 & {$[29,46,58]$} \\
\hline
\end{tabular}

It is possible to see in Table 2 that robotics is the most common device to use but also mechatronics are employed. It should be also mentioned that the most popular type of devices are LEGO in different varieties such as LEGO NXT or LEGO MINDSTORM [27, 34, 38, 39, 46, 56, 58] and Arduino [51, $52,55,57,65,66]$.

\section{E. MQ4 - Classify the methodology applied (Challenge Based Learning, Problem Based Learning and Project Based Learning).}

As commented above the methodologies studied due to their similarities were PBL, PrBL and ChBL. Table 4 shows the distribution of works depending on the applied methodology.

Table 3 shows that the most popular methodology is PrBL and that there are not many initiatives that apply ChBL and Robots of Physical devices. It is necessary also to point out that several of the works posed the application of more than one methodology [24, 27].

\section{CONCLUSIONS}

The first stages of every project needs from the analysis of the existing landscape in the research field. This should be done in advance of the project proposal to support your approach. However, authors have not always time enough to complete a systematic search and analysis of the existing work. In those cases, a key stage for the project will be to set up this background. The present paper has described how this 
was done for the RoboSTEAM project, looking for the employment of PD\&R in Challenge based Learning approaches for the specific context of STEAM Education.

The mapping carried out, after exploring 242 papers from the most relevant bibliographic sources shows than only 54 papers were relevant for the research. The mapping reports allow the researchers to obtain an idea about what was happening with regard to the project main topics. Some of the key issues learned: 1) This is a quite new topic because most of the contributions were published in the last 5 years; 2) The works are mostly focused on the development of some specific competences by the students and/or on the application of concrete tools and techniques; 3) Robotics is the most popular tool to use in this context; and 4) While PBL and PrBL are methodologies very common in the selected papers, there are only a few works about ChBL. With this information the researchers can see the innovation of their project, can use the selected papers as a reference, can detect the main gaps on the research field and can see which are the most common journals and conferences to publish their results.

The next step on this work is to develop the project but also to research about why of this lack of other studies about this topic, something that could be addressed from the more specific perspective of a Systematic Literature Review.

\section{REFERENCES}

[1] F. J. García-Peñalvo and A. J. Mendes, "Exploring the computational thinking effects in pre-university education," Computers in Human Behavior, vol. 80, pp. 407-411, 2018/03/01/ 2018, doi: https://doi.org/10.1016/j.chb.2017.12.005

[2] L. Manovich, Software takes command. A\&C Black, 2013.

[3] A. Tucker, F. Deek, J. Jones, D. McCowan, C. Stephenson, and A. Verno, "A model curriculum for K-12 computer science," Final Report of the ACM K-12 Task Force Curriculum Committee, CSTA, 2003.

[4] P. C. Blumenfeld, E. Soloway, R. W. Marx, J. S. Krajcik, M. Guzdial, and A. Palincsar, "Motivating Project-Based Learning: Sustaining the Doing, Supporting the Learning," Educational Psychologist, vol. 26, no. 3-4, pp. 369-398, 1991/06/01 1991, doi: 10.1080/00461520.1991.9653139.

[5] J. R. Savery and T. M. Duffy, "Problem-Based Learning: An instructional model and its constructivist framework," Educational Technology, vol. 35, no. 5, 1995. [Online]. Available: http://works.bepress.com/john_savery/4 $/$.

[6] L. Johnson and S. Adams, "Challenge Based Learning: The Report from the Implementation Project," The New Media Consortium, Austin, Texas, 2011.

[7] S. Atmatzidou and S. Demetriadis, "Advancing students' computational thinking skills through educational robotics: A study on age and gender relevant differences," Robotics and Autonomous Systems, vol. 75, pp. 661-670, 2016.

[8] M. Merdan, W. Lepuschitz, G. Koppensteiner, and R. Balogh, Robotics in Education - Research and Practices for Robotics in STEM Education (Advances in Intelligent Systems and Computing). Springer International Publishing, 2017.

[9] E. Cejka, C. Rogers, and M. Portsmore, "Kindergarten robotics: Using robotics to motivate math, science, and engineering literacy in elementary school," International Journal of Engineering Education, vol. 22, no. 4, p. 711, 2006.

[10] M. U. Bers, L. Flannery, E. R. Kazakoff, and A. Sullivan, "Computational thinking and tinkering: Exploration of an early childhood robotics curriculum," Computers \& Education, vol. 72, pp. 2014/03/01/ 2014 ,

doi: https://doi.org/10.1016/j.compedu.2013.10.020.

[11] M. Á. Conde et al., "RoboSTEAM - Definition of a Challenge Based Learning Approach for integrating STEAM and develop Computational Thinking. ," presented at the Seventh International
Conference on Technological Ecosystems for Enhancing Multiculturality (TEEM 2019) León, Spain, 2018.

[12] European-Comission, "RoboSTEAM Project Description," 2019. [Online]. Available: https://ec.europa.eu/programmes/erasmusplus/projects/eplus-project-details/\#project/2018-1-ES01-KA201050939

[13] K. Petersen, R. Feldt, S. Mujtaba, and M. Mattsson, "Systematic mapping studies in software engineering," in Ease, 2008, vol. 8, pp. 6877.

[14] K. Petersen, S. Vakkalanka, and L. Kuzniarz, "Guidelines for conducting systematic mapping studies in software engineering: An update," Information and Software Technology, vol. 64, pp. 1-18, 2015.

[15] A. Eguchi, "RoboCupJunior for promoting STEM education, 21st century skills, and technological advancement through robotics competition," Robotics and Autonomous Systems, vol. 75, pp. 692699, 2016.

[16] A. Eguchi, "Educational robotics to promote 21 st century skills and technological understanding among underprivileged undergraduate students," in 2015 IEEE Integrated STEM Education Conference, 2015: IEEE, pp. 76-82.

[17] A. Gomoll, S. Šabanović, E. Tolar, C. E. Hmelo-Silver, M. Francisco, and O. Lawlor, "Between the Social and the Technical: Negotiation of Human-Centered Robotics Design in a Middle School Classroom," International Journal of Social Robotics, journal article vol. 10, no. 3, pp. 309-324, June 01 2018, doi: 10.1007/s12369-017-0454-3.

[18] A. Gomoll, C. E. Hmelo-Silver, S. Šabanović, and M. Francisco, "Dragons, ladybugs, and softballs: Girls' STEM engagement with human-centered robotics," Journal of Science Education and Technology, vol. 25, no. 6, pp. 899-914, 2016.

[19] B. Miller, A. Kirn, M. Anderson, J. C. Major, D. Feil-Seifer, and M. Jurkiewicz, "Unplugged Robotics to Increase K-12 Students' Engineering Interest and Attitudes," in 2018 IEEE Frontiers in Education Conference (FIE), 2018: IEEE, pp. 1-5.

[20] M. Nabeel et al., "Robotics education methodology for K-12 students for enhancing skill sets prior to entering university," in 2017 IEEE International Conference on Robotics and Biomimetics (ROBIO), 5-8 Dec. 2017 2017, pp. 1702-1707, doi: 10.1109/ROBIO.2017.8324663.

[21] S. Ziaeefard et al., "GUPPIE program — A hands-on STEM learning experience for middle school students," in 2017 IEEE Frontiers in Education Conference (FIE), 18-21 Oct. 2017 2017, pp. 1-8, doi: 10.1109/FIE.2017.8190546.

[22] F. Tauro et al., "Integrating mechatronics in project-based learning of Malaysian high school students and teachers," International Journal of Mechanical Engineering Education, vol. 45, no. 4, pp. 297-320, 2017.

[23] F. Ozis, A. Newley, and E. Kaya, "First round evaluation of first tech challenge (FTC) Robotics Club: Does it really prepare students for beyond college," in ASEE Annual Conference \& Exposition, New Orleans, Louisiana, 2016, vol. 10, p. 26905.

[24] M. Barak and M. Assal, "Robotics and STEM learning: students' achievements in assignments according to the P3 Task Taxonomypractice, problem solving, and projects," International Journal of Technology and Design Education, journal article vol. 28, no. 1, pp. 121-144, March 01 2018, doi: 10.1007/s10798-016-9385-9.

[25] A. Merkouris and K. Chorianopoulos, "Programming touch and fullbody interaction with a remotely controlled robot in a secondary education STEM course," presented at the Proceedings of the 22nd Pan-Hellenic Conference on Informatics, Athens, Greece, 2018.

[26] S. Matthiesen, M. Eisenmann, K. Hölz, and O. Six, "EXPERIENCING AND TEACHING TECHNOLOGY-INTEGRATING STEM TEACHING-STUDENTS IN INTERDISCIPLINARY DESIGN TEAMS," in DS 93: Proceedings of the 20th International Conference on Engineering and Product Design Education (E\&PDE 2018), Dyson School of Engineering, Imperial College, London. 6th-7th September 2018, 2018, pp. 636-641.

[27] A. Valls, J. Albó-Canals, and X. Canaleta, "Creativity and Contextualization Activities in Educational Robotics to Improve Engineering and Computational Thinking," in International Conference on Robotics and Education RiE 2017, 2017: Springer, pp. 100-112.

[28] N. Boyer, "Inspiring the Next Generation of Scientists and Engineers: K-12 and Beyond," Computer, vol. 50, no. 7, pp. 17-19, 2017. 
[29] M. Barger and M. A. Boyette, "Do K-12 Robotics Activities Lead to Engineering and Technology Career Choices?," in 2015 ASEE Annual Conference \& Exposition, 2015, pp. 26.557. 1-26.557. 9.

[30] K. Gucwa and H. H. Cheng, "RoboSim for integrated computing and STEM education," in American Society for Engineering Education Annual Conference and Exposition, 2014, pp. 1-17.

[31] J. McLurkin, J. Rykowski, M. John, Q. Kaseman, and A. J. Lynch, "Using Multi-Robot Systems for Engineering Education: Teaching and Outreach With Large Numbers of an Advanced, Low-Cost Robot," IEEE Transactions on Education, vol. 56, no. 1, pp. 24-33, 2013, doi: 10.1109/TE.2012.2222646.

[32] K. Yoshino et al., "Development of Study Aids and Project Activity Procedures for STEM Educatio," in Advanced Materials Research, 2012, vol. 590: Trans Tech Publ, pp. 503-507.

[33] N. Mathers, A. Goktogen, J. Rankin, and M. Anderson, "Robotic mission to mars: Hands-on, minds-on, web-based learning," Acta astronautica, vol. 80, pp. 124-131, 2012.

[34] J. T. Doswell and P. H. Mosley, "Robotics in mixed-reality training simulations: augmenting STEM learning," in Sixth IEEE International Conference on Advanced Learning Technologies (ICALT'06), 2006: IEEE, pp. 864-868.

[35] S. Karaman et al., "Project-based, collaborative, algorithmic robotics for high school students: Programming self-driving race cars at MIT," in 2017 IEEE Integrated STEM Education Conference (ISEC), 11-11 March 2017 2017, pp. 195-203, doi: 10.1109/ISECon.2017.7910242.

[36] L. Hoffmann, S. Franz, T. Eilts, and F. Wallhoff, "Assistive Technologies Summer School: STEM-subjects and robotics," in 2013 International Conference on Advanced ICT and Education (ICAICTE13), 2013: Atlantis Press.

[37] H.-C. Kuo, Y.-C. Tseng, and Y.-T. C. Yang, "Promoting college student's learning motivation and creativity through a STEM interdisciplinary PBL human-computer interaction system design and development course," Thinking Skills and Creativity, vol. 31, pp. 1-10, 2019.

[38] J. Leonard et al., "Using robotics and game design to enhance children's self-efficacy, STEM attitudes, and computational thinking skills," Journal of Science Education and Technology, vol. 25, no. 6, pp. 860-876, 2016.

[39] J. Payton, T. Barnes, J. Black, and C. Seals, "Engaging college students in service learning to grow the K-12 computing pipeline and prepare the 21st century workforce (abstract only)," presented at the Proceedings of the 45th ACM technical symposium on Computer science education, Atlanta, Georgia, USA, 2014.

[40] C. LaPlante, M. Nolin, and T. Saulnier, "PlayScope: augmented microscopy as a tool to increase STEM engagement," presented at the Proceedings of the 12th International Conference on the Foundations of Digital Games, Hyannis, Massachusetts, 2017.

[41] D. A. Fields, Y. B. Kafai, T. Nakajima, and J. Goode, "Teaching Practices for Making E-Textiles in High School Computing Classrooms," presented at the Proceedings of the 7th Annual Conference on Creativity and Fabrication in Education, Stanford, CA, USA, 2017.

[42] A. Connors-Kellgren, C. E. Parker, D. L. Blustein, and M. Barnett, "Innovations and Challenges in Project-Based STEM Education: Lessons from ITEST," Journal of Science Education and Technology, journal article vol. 25, no. 6, pp. 825-832, December 01 2016, doi: 10.1007/s10956-016-9658-9.

[43] C. Wongwatkit, P. Prommool, R. Nobnob, S. Boonsamuan, and R. Suwan, "A Collaborative STEM Project with Educational Mobile Robot on Escaping The Maze: Prototype Design and Evaluation," in International Conference on Web-Based Learning, 2018: Springer, pp. 77-87.

[44] S. Hutamarn, S. Chookaew, C. Wongwatkit, S. Howimanporn, T. Tonggeod, and S. PANJAN, "A stem robotics workshop to promote computational thinking process of pre-engineering students in thailand: Stemrobot," in The 25th International Conference on Computers in Education, 2017, pp. 514-522.

[45] J. Cross, E. Hamner, L. Zito, and I. Nourbakhsh, "Engineering and Computational Thinking talent in middle school students: A framework for defining and recognizing student affinities," in 2016 IEEE Frontiers in Education Conference (FIE), 12-15 Oct. 2016 2016, pp. 1-9, doi: 10.1109/FIE.2016.7757720.

[46] B. K. M. K. Pedersen, K. E. Andersen, A. JØrgensen, S. Köslich, F. Sherzai, and J. Nielsen, "Towards playful learning and computational thinking - Developing the educational robot BRICKO," in 2018 IEEE Integrated STEM Education Conference (ISEC), 10-10 March 2018 2018, pp. 37-44, doi: 10.1109/ISECon.2018.8340502.

[47] R. Burbaitė, V. Drąsute, and V. Štuikys, "Integration of computational thinking skills in STEM-driven computer science education," in 2018 IEEE Global Engineering Education Conference (EDUCON), 17-20 April 2018 2018, pp. 1824-1832, doi: 10.1109/EDUCON.2018.8363456.

[48] A. Bermúdez, R. Casado, G. Fernández, M. Guijarro, and P. Olivas, "Drone challenge: A platform for promoting programming and robotics skills in K-12 education," International Journal of Advanced Robotic Systems, vol. 16, no. 1, p. 1729881418820425, 2019.

[49] C. Kim, J. Yuan, L. Vasconcelos, M. Shin, and R. B. Hill, "Debugging during block-based programming," Instr Sci, vol. 46, no. 5, pp. 767787, 2018.

[50] M. S. Taylor, "Computer Programming With Pre-K Through FirstGrade Students With Intellectual Disabilities," The Journal of Special Education, vol. 52, no. 2, pp. 78-88, 2018/08/01 2018, doi: 10.1177/0022466918761120.

[51] S. Psycharis and E. Kotzampasaki, "A Didactic Scenario for Implementation of Computational Thinking using Inquiry Game Learning," presented at the Proceedings of the 2017 International Conference on Education and E-Learning, Bangkok, Thailand, 2017.

[52] R. Feldhausen, J. L. Weese, and N. H. Bean, "Increasing Student SelfEfficacy in Computational Thinking via STEM Outreach Programs," presented at the Proceedings of the 49th ACM Technical Symposium on Computer Science Education, Baltimore, Maryland, USA, 2018.

[53] A. R. Basawapatna, A. Repenning, K. H. Koh, and M. Savignano, "The consume - create spectrum: balancing convenience and computational thinking in stem learning," presented at the Proceedings of the 45th ACM technical symposium on Computer science education, Atlanta, Georgia, USA, 2014.

[54] J. Gorson, N. Patel, E. Beheshti, B. Magerko, and M. Horn, "TunePad: Computational Thinking Through Sound Composition," presented at the Proceedings of the 2017 Conference on Interaction Design and Children, Stanford, California, USA, 2017.

[55] S. R. Pandian, "Playful STEAM Learning Using Robots," in 2018 IEEE International Conference on Teaching, Assessment, and Learning for Engineering (TALE), 4-7 Dec. 2018 2018, pp. 279-285, doi: 10.1109/TALE.2018.8615299.

[56] B. Elmore, "Conducting project-based learning with a large chemical engineering freshman cohort using LEGO NXT robotics," in American Society for Engineering Education Annual Conference, 2014.

[57] M. Saleiro, B. Carmo, J. M. F. Rodrigues, and J. M. H. du Buf, "A Low-Cost Classroom-Oriented Educational Robotics System," Cham, 2013: Springer International Publishing, in Social Robotics, pp. 74-83.

[58] D. B. Larkins, J. C. Moore, L. J. Rubbo, and L. R. Covington, "Application of the cognitive apprenticeship framework to a middle school robotics camp," presented at the Proceeding of the 44th ACM technical symposium on Computer science education, Denver, Colorado, USA, 2013.

[59] Y. Chen, C. Chang, and K. Tseng, "The instructional design of integrative STEM curriculum: A pilot study in a robotics summer camp," in 2015 International Conference on Interactive Collaborative Learning (ICL), 20-24 Sept. 2015 2015, pp. 871-875, doi: 10.1109/ICL.2015.7318142.

[60] C. Hartigan and G. Hademenos, "Introducing ROAVEE: An Advanced STEM-Based Project in Aquatic Robotics," The Physics Teacher, vol. 57, no. 1, pp. 17-20, 2019.

[61] A. Peixoto et al., "Robotics tips and tricks for inclusion and integration of students," in 2018 IEEE Global Engineering Education Conference (EDUCON), 17-20 April 2018 2018, pp. 2037-2041, doi: 10.1109/EDUCON.2018.8363487.

[62] E. Serrano Pérez and F. Juárez López, "An ultra - low cost line follower robot as educational tool for teaching programming and circuit's foundations," Computer Applications in Engineering Education, vol. 27, no. 2, pp. 288-302, 2019.

[63] A. Sullivan and E. K. Johnson, "BeadED Adventures: Crafting STEM Learning," presented at the Proceedings of the Thirteenth International Conference on Tangible, Embedded, and Embodied Interaction, Tempe, Arizona, USA, 2019.

[64] A. Phalke, M. Biller, S. Lysecky, and C. Harris, "Non-expert construction of customized embedded systems to enhance STEM 
curricula," SIGBED Rev., vol. 6, no. 1, pp. 1-11, 2009, doi: $10.1145 / 1534480.1534488$.

[65] D. Ball, C. Tofel-Grehl, and K. A. Searle, "Sustaining Making in the Era of Accountability: STEM Integration Using E-Textiles Materials in a High School Physics Class," presented at the Proceedings of the 7th Annual Conference on Creativity and Fabrication in Education, Stanford, CA, USA, 2017.

[66] K. J. Scheltenaar, J. E. C. van der Poel, and M. M. Bekker, "DesignBased Learning in Classrooms Using Playful Digital Toolkits," Cham, 2015: Springer International Publishing, in Entertainment Computing ICEC 2015, pp. 126-139.
[67] C. Chung, C. Cartwright, and J. DeRose, "Robotics Festival and Competitions Designed for STEM $+\mathrm{C}$ Education," in Robotics in STEM Education: Redesigning the Learning Experience, M. S. Khine Ed. Cham: Springer International Publishing, 2017, pp. 131-170.

[68] G. Bull, N. Standish, E. Johnson, and H. Haj-Hariri, "Educational Leadership and Planning for Digital Manufacturing in Schools," in ICT in Education in Global Context: Comparative Reports of Innovations in K-12 Education, R. Huang, Kinshuk, and J. K. Price Eds. Berlin, Heidelberg: Springer Berlin Heidelberg, 2016, pp. 173-194. 